\title{
EL ESTADO-NACIÓN Y LA UNIÓN \\ EUROPEA. ¿HACIA UNA NECESARIA REFORMULACIÓN \\ DE LO ESTATAL?
}

\section{Eduardo TORRES ESPINOSA*}

RESUMEN: Los últimos acontecimientos en Europa han reavivado un viejo debate al interior de las ciencias sociales, incluido el derecho constitucional y el internacional: ¿Tiene futuro el orden internacional westfaliano basado en el Estado-nación y en la noción de soberanía estatal? En este artículo se argumenta que la sólida estructura institucional supranacional construida por la Unión Europea y, hoy, la posibilidad de darle una Constitución sugieren el desarrollo de una forma de organización política sin precedentes. El carácter supranacional de las instituciones europeas representa una innovadora respuesta a la naturaleza transnacional de los grandes retos que hoy se enfrentan. Así, la transformación del Estado-nación provocada por la experiencia europea justifica una reformulación de lo estatal.

ABSTRACT: The latest events in Europe have stoked up an old debate within the social sciences, including the constitutional and international law: Has the Westphalian international order based on the nation-State and in the notion of state sovereignty any future? This article argues that the solid supranational institutional structure built by the European Union and, today, the possibility of giving it a constitution suggest the development of a form of political organization without precedents. The supranational character of the European institutions represents an innovative response to the transnational nature of the great challenges we deal with. So, the transformation of the nation-State, caused by the European experience, justify a reformulation of the State nature.

RÈSUMĖ: Les derniers événements en Europe ont fait renaître le vieux débat commun aux sciences sociales, inclus le droit constitutionnel et le droit international: At-il un future l'ordre international westphalien qui a comme fondement l'Etat-nation et le concept de souveraineté étatique? Dans cet article on analyse la structure supranationale solidement construite par l'Union Européenne et la possibilité, aujourd'hui, de lui donner une constitution, ce qui suggère le développement d'une forme d'organisation politique qui ne connaît pas des précédents. Le caractère supranational des institutions européennes offre une réponse innovatrice á la nature multinationale des grands défis auxquels elles y doivent faire face. Ainsi, la transformation de l'Etat-nation provoquée par l'expérience européenne justifie une nouvelle formulatión de la notion étatique.

* Maestro en políticas públicas por la Universidad de Exeter, Inglaterra; doctor en gobierno por la London School of Economics; y profesor en la Facultad de Estudios Superiores Acatlán de la UNAM.

Anuario Mexicano de Derecho Internacional, vol. VI, 2006, pp. $551-575$ 
Ni ahora ni nunca permitiré que entre el Dios del cielo y mi país se deslice una hoja escrita a guisa de segunda Providencia.

Friedrich Wilhelm IV, 11 de abril de 1847.

SUMARIO: I. Introducción. II. El Estado-nación en tiempos de globalización. III. El mercado común y la supra-institucionalidad de la Unión Europea. IV. Dos problemas con los grandes paradigmas disciplinares. V. El derecho constitucional e internacional ante el caso europeo. VI. Pero, ¿tiene futuro el proyecto constitucional europeo? VII. Reflexiones finales.

\section{INTRODUCCIÓN}

El prolongado debate sobre la posibilidad de dotar una Constitución a la Unión Europea, así como los últimos eventos relacionados con la ratificación del "Tratado por el cual se instituye una Constitución para Europa" —el cual fue aprobado unánimemente por los Estados miembros y luego rechazado en dos referéndum - no sólo han reavivado la vieja discusión en torno al tipo de integración que debe prevaler en Europa, sino que ha tocado fibras aún más sensibles. Como resultado se intenta abordar, más que nunca antes, la pregunta: ¿Cuál es, o debiera ser, el papel del Estado-nación en el nuevo orden internacional?

Esta interrogante ocurre en tiempos en los que los impredecibles efectos de la llamada globalización parecen contradecir el trabajo diario de los analistas más serios y dedicados. No obstante, en este artículo intentaremos dar una respuesta preliminar a dicha pregunta. Para ello tomaremos como estudio de caso a la Unión Europea. El objetivo es contribuir a la clarificación de conceptos clave tales como: Estado-nación, soberanía y, en general, orden westfaliano. Nuestro argumento central es que la UE constituye algo más que una simple alianza internacional de Estados que tienen, o buscan, intereses económicos comunes.

La hipótesis central de trabajo es que la UE constituye una forma de organización política sin precedentes que hoy se articula y, con frecuencia, se confronta con los Estados que la integran. Esta problemática interacción exhibe signos de que la naturaleza del Estado westfaliano, por lo menos en el contexto europeo, se está transformado. No obstante, mientras se discute una Constitución para la UE, los Estados miembros parecen estar más interesados en lo que acontece dentro de sus cada vez más 
nebulosas fronteras territoriales que en cambio revolucionario que hoy tiene lugar en Europa.

Luego de discutir el papel del Estado-nación en tiempos de globalización, se hará referencia a los ingredientes institucionales del mercado común europeo como fuentes de su éxito comercial. Más adelante se hablará de los problemas que enfrentan los enfoques teóricos convencionales para explicar el fenómeno europeo. Aquí, se concederá un lugar especial al papel del derecho tanto como agente de cambio, como de freno. Finalmente se contextualizará la situación constitucional europea a la luz de los últimos eventos.

\section{EL ESTADO-NACIÓN EN TIEMPOS DE GLOBALIZACIÓN}

En las últimas dos décadas, uno de los temas más debatidos en el ámbito académico ha sido el impacto que la intensificación sin precedentes de los intercambios, interdependencias e interconexiones económicas a nivel global, ha tenido sobre el llamado Estado-nación. Sobre el particular existen dos posturas extremas. Por un lado, están los que pronostican el fin del Estado-nación como resultado de los radicales cambios en su entorno y, por el otro, los que sostienen que dicha forma de organización política continuará siendo el principal actor del sistema internacional. ${ }^{1}$

Antes de plantear nuestra posición al respecto conviene indicar que se entiende en este artículo por Estado-nación. ${ }^{2}$ A la caída del Imperio Romano siguió, en el plano fáctico, una fragmentación y "privatización" del poder político por parte de una pluralidad de terratenientes o señores feudales cuyas propiedades servían como la unidad económica básica, misma que los dotaba de autoridad política real. ${ }^{3}$ Sin embargo, la inestabilidad y debilidad de los arreglos políticos y militares feudales, a la que

1 López Ayllón, Sergio, “Globalización’ y transición del Estado nacional”, en González, Maria del Refugio y López-Ayllón, Sergio (eds.), Transiciones y diseños institucionales, primera reimpresión, México, Instituto de Investigaciones Jurídicas de la UNAM, serie Doctrina Jurídica, núm. 3, 2000, p. 303.

2 A partir de este momento, se utilizarán los conceptos Estado-nación y Estado como sinónimos.

3 McLean, Iain y McMillan, Alister, Concise dictionary of politics, segunda edición, Oxford, Oxford University Press, 2003, pp. 512-513. 
contribuyó el advenimiento del capitalismo, conducirían al desarrollo gradual de poderosas monarquías en Europa.

Un momento estelar en este proceso está representado por los tratados de Westfalia de 1648, los cuales no sólo marcaron el fin de las interminables guerras entre España, Holanda y Alemania, sino que sentaron las bases para un nuevo orden europeo. ${ }^{4}$ En efecto, como resultado de la llamada Paz de Westfalia, alrededor de 300 príncipes se convirtieron en los soberanos absolutos dentro de sus dominios originales o ampliados. Esta distribución de poder territorial reemplazó por completo la ya muy deteriorada autoridad central del Sacro Imperio Romano, mismo que sería eventualmente disuelto en 1806.

De esta manera, la soberanía territorial se convirtió en un atributo característico y exclusivo de los nacientes Estados. Gracias a ella, estos últimos podían atender sus asuntos internos sin influencias o perturbaciones externas, así como participar en la arena internacional a través de relaciones diplomáticas, la celebración de tratados, o bien recurriendo al recurso extremo, pero legítimo, de la guerra. Tanto el derecho interno como el desarrollo de ejércitos nacionales jugarían un papel crucial tanto para legitimar como para proteger esta novedosa asignación territorial del poder político. ${ }^{5}$

Como se desprende de lo anterior, la emergencia del Estado-nación fue detonada por cambios significativos en la estructura económica y social, eventos que a su vez tuvieron el efecto de modificar la distribución existente de poder político y por tanto la forma de gobierno. Asimismo, el desarrollo del capitalismo así como el reconocimiento de un número cada vez mayor de derechos políticos a una pujante burguesía explica no sólo la instauración del absolutismo, sino también su tránsito al constitucionalismo democrático o Estado de derecho. ${ }^{6}$

4 Se hace referencia a las negociaciones llevadas a cabo, desde 1644, en los pueblos de Münster y Osnabrück de la región de Westfalia que culminaron con la firma de un tratado entre los españoles y los holandeses en enero de 1648 y otro firmado por el emperador Fernando III, Francia, Suecia y los príncipes alemanes, suscrito en octubre de 1648. "Westphalia, peace of", Encyclopcedia Britannica 2004, Deluxe edition CD, 2004.

5 Un excelente análisis de estos desarrollos puede encontrarse en Giddens, Anthony, The nation-state and violence, Cambridge, Polity Press, 1987.

6 Si se desea abundar sobre este asunto, véase Caballero, José Antonio, "La transición del absolutismo al Estado de derecho", en González, Maria del Refugio y López-Ayllón, Sergio (eds.), Transiciones y diseños institucionales, primera reimpresión, México, Instituto de Investigaciones Jurídicas de la UNAM, serie Doctrina Jurídica, núm. 3, 2000, pp. 19-47. 
El sistema westfaliano alcanza su máximo esplendor en la primera mitad del siglo XX, con una intervención muy significativa del Estado en los procesos económicos. No obstante, las profundas transformaciones que han tenido lugar en el mundo a partir de entonces generaron una floreciente literatura que planteaba la crisis del orden internacional basado en el Estado-nación y en la noción de soberanía estatal. Para el ala más radical, ese orden debe ser visto como un fenómeno en vías de extinción, por lo que el transitar "más allá del estado soberano debe considerarse como algo bueno, como un desarrollo totalmente bienvenido en la historia de las ideas jurídicas y políticas". ${ }^{7}$

En general, esta literatura intenta sustentar que ha tenido lugar una transferencia de poder de los Estados-nación a otros actores, lo que ha originado conflictos de soberanía. Se ha indicado que ese fenómeno se ha manifestado en "tres direcciones": hacia abajo, hacía arriba y lateralmente. ${ }^{8}$ Por lo que hace a la primera dirección, se afirma que los principales beneficiarios de la descentralización han sido el gobierno local y ciertos actores políticos nacionales o regionales, los cuales exhiben un papel más autónomo en el ámbito domestico y más activo en el contexto internacional. ${ }^{9}$

Hacia arriba, se señala que la soberanía del Estado se ha visto amenazada por el desarrollo de entidades "supra-estatales" y "no estatales", así como por la consolidación de las grandes corporaciones económicas transnacionales. Entre las primeras se mencionan de manera reiterada a la Unión Europea en el plano regional, y a la Organización Mundial de Comercio y al Consejo de Seguridad de las Naciones Unidas en el plano global. Respecto a las segundas se llama la atención sobre la proliferación de organizaciones no gubernamentales (ONG) de carácter transnacional, muchas de las cuales con la capacidad real de bloquear, revertir, modificar o retardar la acción de los gobiernos nacionales.

Por lo que toca a las grandes corporaciones económicas se indica que operan al margen de nacionalidades y fronteras en perjuicio de la noción

7 MacCormick, Neil, "Beyond the sovereign State", Modern Law Review, vol.56, 1993, p. 1.

8 Esta idea y su explicación está basada en Valaskakis, Kimon, "Westfalia II: por un nuevo orden mundial”, revista Este País (México), número 126, septiembre de 2001, pp. 5 y ss.

9 Keating, Michel, Plurinational democracy: Stateless nations in a post-sovereignty era, Oxford, Oxford University Press, 2001.Un buen ejemplo de ello lo constituye la impugnación por la firma del protocolo de Kyoto que hizo la provincia canadiense de Alberta al gobierno central bajo el argumento de que no fue previamente consultada. 
de soberanía territorial. Un dato ilustra la importancia de estos agentes. Según la revista Fortune, en 1999 las cien economías del mundo estaban constituidas por 51 corporaciones transnacionales y 49 países, con una tendencia al aumento del número de las primeras en la lista y a su poder económico real. Ahí se puede ver, por ejemplo, que en ese año la suma de los activos de sólo tres empresas (General Motors, Wal-Mart y Exxon) fue superior al PIB de México.

Finalmente, se considera que lateralmente el Estado-nación ha cedido poder hacia las fuerzas del mercado, a través de políticas deliberadas de desregulación y privatización, la disminución del gasto público, así como la firma de tratados de libre comercio. Con estas medidas, se subraya, muchos Estados han efectuado un repliegue estratégico a favor de los agentes económicos trasnacionales. Así, se concluye que esta transferencia de poder, junto con las dos anteriores, contradice la idea de que el Estado es el poder supremo tanto en el ámbito interior como en el exterior.

A pesar de todo lo anterior, un número importante de autores consideran al Estado-nación como el actor central del nuevo orden nacional e internacional. ${ }^{10} \mathrm{Su}$ argumento central parte de la diferencia que existe entre los Estados que funcionan conforme al modelo económico y político occidental y aquellos que no han transitado plenamente al capitalismo y a la democracia. Enseguida, subrayan el hecho de que fue en el interior de los primeros Estados donde "se produjeron las condiciones económicas y tecnológicas de la globalización", por lo que este proceso debe ser visto como "la culminación de la expansión de los Estados europeos en el resto del mundo". ${ }^{11}$

Por lo anterior, las democracias industrializadas occidentales, incluidos los Estados que han seguido su ejemplo, son los que obtienen y obtendrán los mayores beneficios de la globalización, mientras que el resto de los Estados son los que están pagando y continuarán pagando los costos de sus disfunciones estructurales y su limitada integración a la economía global. De esta manera, si uno de los efectos de la globalización fuera la futura desaparición del Estado-nación — como sostiene la primera

10 Walker, Neil, "The idea of constitutional pluralism", Florencia, European University Institute, Departamento de Derecho, serie EUI Working Papers, núm.02-01, 2002.

11 Vitale, Ermanno, "Globalización y Estado de derecho", revista Este País (México), núm. 139 , octubre de 2002 , p. 8. 
tesis analizada en esta sección- los Estados menos desarrollados estarían en una situación de mayor riesgo.

En clara referencia al mundo desarrollado, un reporte reciente del Consejo de Nacional de los Estados Unidos pronostica que para el 2020 el "Estado-nación continuará siendo la unidad dominante del orden global" y que aquél país "influirá en el camino que actores tanto estatales como no estatales decidan recorrer". Aunque el mismo documento también reconoce que "la globalización económica y la dispersión de tecnologías, especialmente de las tecnologías informáticas, ejercerán nuevas y enormes tensiones sobre los gobiernos [nacionales]". ${ }^{12}$

Frente a las dos posturas anteriores, nuestra opinión es que no existe evidencia que permita augurar la extinción del Estado-nación como resultado de la globalización económica. A diferencia, si existen algunos indicadores que permiten sustentar la idea de que tanto dicho proceso como la emergencia de instituciones supra-nacionales sin precedentes están transformando al Estado-nación, como lo demuestra la experiencia europea de integración.

\section{EL MERCADO COMÚN Y LA SUPRA-INSTITUCIONALIDAD DE LA UNIÓN EUROPEA}

Una línea de interpretación todavía muy extendida sostiene que una de las características más sobresalientes de la globalización económica es la rápida expansión del comercio mundial y que son las corporaciones económicas más grandes del mundo los principales responsables de esa expansión. Estos agentes tienden a instalarse en los lugares que ofrezcan recursos y mano de obra más baratos. Para evitar la fuga de capitales, concluye el argumento, es de esperarse que los países más industrializados reduzcan impuestos y gasto público, constriñan sus políticas sociales y flexibilicen sus mercados laborales. ${ }^{13}$

Sin embargo, la evidencia que se ha ido acumulando en los últimos años no sustenta y, en muchos casos, contradice lo anterior. Para comen-

12 Mapping the global future: Report of the National of the National Intelligence Council's 2020 (Based on consultations with nongovernmental experts around the world), Washington D.C., National Intelligence Council, diciembre de 2004, pp. 1 y 5.

13 Para una amplía reseña de la literatura que sostiene lo anterior, véase a Schulze, G. G. y Urprung, H. W., "Globalisation of the economy and the nation-state", The World Economy, vol. 22. núm. 3, 1999, pp. 308-322. 
zar, el incremento del comercio mundial no es tan notable como se hace parecer. ${ }^{14}$ En los países más desarrollados, una mayor actividad económica y apertura comercial ha sido acompañada por un aumento en los niveles de impuestos, de gasto público y aun de protección social. Una explicación es que los agentes económicos buscan infraestructura física de calidad, mano de obra productiva y, sobre todo, estabilidad política y social, más que simplemente recursos y mano de obra baratos. ${ }^{15}$

Más reveladora aún es la observación de que la intensificación del comercio mundial ha sido provocada, en buena medida, por el mercado europeo. En este sentido, se ha argumentado que lo que ha tenido lugar en Europa en los últimos cuarenta años no ha sido un proceso de globalización, como generalmente se piensa, sino de "des-globalización" (de-globalisation) como resultado de la integración europea y de la efectiva construcción de un muy bien integrado mercado único en la región. ${ }^{16}$ De manera similar, Fligstein y Merand plantean la audaz tesis de que lo que generalmente llamamos globalización es, en realidad, "europeanización" (Europeanization). ${ }^{17}$

Algunos datos ayudan a entender mejor lo anterior. El proceso de integración europea inició en 1951 con la creación de la Comunidad Europea del Carbón y del Acero. Con ello se buscó estabilizar la producción de acero en Europa para impedir la competencia desleal y, de esta manera, favorecer la reconstrucción. El Tratado de Roma de 1957 expandió las actividades del naciente mercado común europeo a otros sectores y redujo las tarifas comerciales con el fin de promover el libre comercio y el crecimiento económico. Detrás de estas acciones estuvo siempre la idea de que la integración de las economías europeas inhibiría la amenaza de conflictos bélicos en la región, tal como ha sucedido.

Gracias a la consolidación de un exitoso mercado regional, el comercio al interior de la Unión Europea (UE) se ha incrementado notablemen-

14 Bairoch, Paul, "Globalization, myths and realities: One century of external trade and foreign investment”, en Boyer, Robert y Drache, Daniel (eds.), States against markets: The limits of globalization, Londres, Routledge, 1996.

15 Fligstein, Neil y Merand, Frederic, "Globalization or Europeanization? Evidence of the European economy since 1980", Center for Culture, Organizations and Politics de la Universidad de California en Berkeley, Ensayo núm. WPS-02, 2001.

16 Hay, Colin, “Globalisation, 'EU-isation' and the space for social democratic alternatives: pessimism of the intellect: a reply to Coates", British Journal of Politics and International Relations, vol. 4, núm. 3, octubre de 2002, pp. 452-464.

17 Fligstein, Neil y Merand, Frederic, op. cit., nota 15, p. 6. 
te en los últimos cuarenta años. ${ }^{18}$ En 2000, por ejemplo, el comercio entre los países europeos representó, en promedio, el 40 por ciento de sus respectivos PIB, mientras que el 70 por ciento de sus exportaciones fueron hechas entre dichos países. Estos hechos sugieren que las grandes multinacionales europeas, y algunas no europeas, han orientado sus inversiones y sus políticas comerciales hacia el mercado europeo. Como resultado de todo lo anterior, la UE se ha convertido en "zona económica más densa en el mundo con excepción de los Estados Unidos". ${ }^{19}$

¿Qué explica el éxito comercial de la UE? Desde la perspectiva del nuevo institucionalismo económico, la construcción de un mercado económico regional bien integrado y eficiente $\mathrm{y}$, por lo tanto, estable, implica necesariamente la existencia de "reglas de juego". ${ }^{20}$ La relevancia de estas reglas está asociada con su función de defender los derechos de propiedad de los actores, así como los términos de sus intercambios, cooperación y competencia. Y lo anterior no sería posible sin la existencia de instituciones supranacionales cuya tarea sería la proveer dichas reglas y garantizar su aplicación, así como la de formular las políticas también supranacionales que demande el buen funcionamiento del mercado común. ${ }^{21}$

Más allá de lo estrictamente económico, la novedad del edificio institucional construido por la UE radica precisamente en su carácter supranacional y en el impacto que sus crecientes atribuciones ha tenido sobre los Estados que la integran. Como resultado, la lista de cambios que ponen en tela de juicio la noción de Estado-nación y que sugieren el desarrollo de una forma supranacional de gobernación nunca antes vista, va en aumento. En un nivel macro, destacan dos cambios íntimamente relacionados: el desplazamiento de la toma de decisiones de los ámbitos nacionales al comunitario y el desarrollo de un derecho "comunitario" que

18 OECD, The European Union's trade policies and their economics, París, Organisation for Economic Co-operation and Development, 2000.

19 Fligstein, Neil y Merand, Frederic, op. cit., nota 15, p. 6.

20 North, Douglass C., Institutions, institucional change and economic performance, Cambridge, Cambridge University Press, 1990.

21 Sobre la importancia y papel de las instituciones en la vida política, véase a March, James G. y Olsen, Johan P., El redescubrimiento de las instituciones: La base organizativa de la politica, México, FCE-Colegio Nacional de Ciencias Políticas y Administración Pública, colección Nuevas Lecturas de Política y Gobierno, 1997; y a Peters, Guy B., El nuevo institucionalismo: Teoría institucional en ciencia política, primera edición, Barcelona, Gedisa, colección Ciencia Política, 2003. 
le da vida a la UE, regula su actividad y hace jurídicamente obligatorias sus decisiones y políticas.

Parece claro que hoy, la UE penetra profundamente las estructuras políticas y gubernamentales de los Estados miembros. Aunque la pregunta central que ello plantea es: ¿Hasta que punto la acción de la EC está determinada por las de los gobiernos nacionales?, o, dicho de otro modo, ¿cuál es la participación de dichos gobiernos en la toma de decisiones comunitarias? Aunque las respuestas están divididas, la explicación cada vez más popular es que la gobernación territorial de los Estados miembros se ha visto gradual, pero significativamente, limitada por las complejas estructuras y mecanismos decisorios de la UE. ${ }^{22}$

Como resultado, el argumento de que la soberanía de los Estados miembros de la UE no ha sido tocada por el proceso de integración ha comenzado a ser severamente cuestionado desde muy diversos frentes. Una de ellas deriva de los resultados que ha aportado el estudio sistemático y cada vez más profundo de la UE como un "sistema de gobernación" (system of governance) que se ejerce en múltiples niveles (multi-level governance)..$^{23}$ Esta perspectiva intenta desentrañar, por niveles y sectores, cómo trabajan los muy intrincados sistemas de toma de decisiones dentro de la UE, así como identificar, caso por caso, a las instituciones y actores más influyentes. ${ }^{24}$

La otra gran causa de que los Estados miembros de la UE estén gradualmente perdiendo soberanía lo constituye el derecho comunitario y el papel crecientemente importante que están jugando los órganos jurisdiccionales europeos encargados de su aplicación..$^{25}$ Actualmente, el derecho primario de la UE está constituido por todos los tratados que han

22 Trondal, Jarle, "Two worlds of Europeanisation: Unpacking models of government innovation and transgovernmental imitation", European Integration online Papers, vol. 9, núm. 1, enero de 2005 (disponible en http://eiop.or.at/eiop/texte/2005-001a.htm).

23 Torres Espinosa, "Integración europea y globalización. Una perspectiva institucional", Anuario Mexicano de Derecho Internacional, vol. 5, 2005, p. 507. Para un resumen del desarrollo de esta nueva literatura, véase a Hix, Simon, 1998: "The study of the European Union II: the "new governance' agenda and its rival”, Journal of European Public Policy, vol. 5, núm. 1, 1998, pp. 38-65.

24 Eberlein, Burkard y Kerwer, Dieter, "Theorising the New Modes of European Union Governance", European Integration Online Papers, vol. 6, núm. 5, abril de 2002 (disponible en http://eiop.or.at/eiop/texte/2002-005a.htm); Peterson, John, "Decision-making in the European Union: Towards a framework for analysis”, Journal of European Public Policy, vol. 2, núm. 1, marzo de 1995, pp. 69-93.

25 De Búrca, Gráinne., "Sovereignty and the supremacy doctrine of the European Court of Justice", en Walker, Neil. (ed.), Sovereignty in transition, Oxford, Hart, 2003. 
suscrito los Estados miembros a partir del Tratado de París de 18 de abril de 1951, mismo que creó la Comunidad Europea del Carbón y el Acero. ${ }^{26} \mathrm{La}$ importancia de este cuerpo normativo radica en su primacía sobre el derecho constitucional nacional en las áreas reservadas a la UE. O dicho de otra manera, en caso de conflicto los jueces nacionales deben preferir el derecho comunitario a las leyes de sus propios Estados.

A un nivel menos general, la UE proporciona muchos ejemplos que ponen en tela de juicio el concepto tradición de soberanía estatal, pero uno sobresale. La introducción del euro - luego del Tratado de Maastricht del 7 de febrero de 1992 - tuvo el efecto de transferir al ámbito de la UE "uno de los tres derechos soberanos del Estado-nación": la moneda. Por lo que hace a los otros dos, esto es, la seguridad interior y la seguridad exterior, la UE discute desde hace ya algún tiempo la posibilidad de enfrentar las amenazas internas a nivel europeo, así como la necesidad de contar con una política exterior y aun militar común. ${ }^{27}$

Hasta este punto, el caso Europeo plantea, por lo menos, dos preguntas centrales. Si el Estado-nación se está transformando, ¿ante que realidad político-jurídica nos encontramos? Frente a la atipicidad de la UE, ¿cómo catalogar a esta nueva "especie institucional", pero sobre todo cómo entender lo que significa su emergencia en el nuevo orden mundial? Ambas preguntas han puesto en serios aprietos a los actuales enfoques teóricos como vamos a ver a continuación.

\section{DOS PROBLEMAS CON LOS GRANDES PARADIGMAS DISCIPLINARES}

A causa de la creciente interdependencia entre los ámbitos doméstico e internacional que ha generado la globalización en todos los terrenos, cada vez es más difícil encontrar la línea divisoria entre dichas esferas. Este hecho se ha reflejado en el campo de las ciencias sociales. Así, se ha notado el debilitamiento del antes casi infranqueable muro disciplinario que antes separaba a la ciencia política de las "relaciones internaciona-

26 Tamames, Ramón, La Unión Europea, 3a. ed., Madrid, Alianza Editorial, núm. 146, 1996, serie Alianza Universidad Textos, pp. 69 y ss.

27 Fisher, Joschka, "From confederation to federation: Thoughts on the finality of European integration", The Federal Trust for Education \& Research, European Essay, núm. 8, 2000. 
les". ${ }^{28}$ Lo mismo puede decirse del derecho constitucional y el internacional, de la ciencia política y la economía, del derecho y la economía, de la ciencia política y el derecho, por mencionar sólo algunos ejemplos. Pareciera como si las ciencias sociales se estuvieran también "globalizando".

Al mismo tiempo, la novedad de la globalización y la profundidad y, sobre todo, velocidad de los cambios que ha provocado la nueva "revolución tecnológica" está reduciendo la capacidad explicativa de la mayoría de los enfoques teóricos convencionales, así como debilitando los paradigmas que han construido y sobre los cuales se sostienen. Un buen ejemplo lo proporciona la crisis del concepto de soberanía en que se cimientan las teorías del Estado-nación que han elaborado la ciencia política, el derecho, la filosofía política y la filosofía del derecho.

\section{1. ¿Soberanía o "post-soberanía”?}

Según la perspectiva westfaliana, la soberanía ha sido entendida como la demanda de los Estados de ser "la última autoridad política, no sujeta a un poder más alto por lo que hace a la elaboración e imposición de las decisiones políticas". ${ }^{29}$ En las últimas décadas, sin embargo, el viejo paradigma de la soberanía ha sido sometido a la prueba del ácido tanto por la teoría como por la práctica, lo que ha dividido a los científicos sociales. A ello ha contribuido el reconocimiento - hecho por algunos de ellos- de que "el poder de la comunidad internacional se ha fortalecido en detrimento de la soberanía estatal" por muy diversas causas. ${ }^{30}$

Entre ellas se encuentran la transferencia de atribuciones que los Estados han hecho, voluntaria o involuntariamente, a las organizaciones internacionales o supranacionales como en el caso de la UE, ${ }^{31}$ el desarrollo del ius cogens, la internacionalización de los derechos humanos, el

28 Hay, Colin, Political analysis: A critical introduction, Nueva York, Palgrave, serie Political Analysis, 2002, pp. 3-5. Se hace referencia aquí a las "relaciones internacionales" como una disciplina académica independiente.

29 McLean, Iain y McMillan, Alister, op. cit., nota 3, p. 502.

30 Besson, Samantha, "Sovereignty in conflict", European Integration Online Papers, vol. 8, núm. 15, 2004, p. 2 (disponible en http/leiop.or.at/eiop/texte/2004-015a.htm).

31 Si se desea abundar sobre este tema, véase a Keating, Michel, "Europe's changing landscape: Territorial restructuring and new forms of government, en Beaumont, Paul, Lyons, Carole y Walker, Neil (eds.), Convergence and Divergence in European Public Law, Oxford, Hart, 2001. 
fortalecimiento del principio de intervención humanitaria y la "globalización jurídica". Esta evidencia ha provocado un ya largo debate académico sobre si la condición "normal" de los Estados continua siendo "la de ser el poder supremo o la última autoridad en asuntos políticos y jurídicos, tanto interna como externamente" y, como resultado, sobre la utilidad real del concepto de soberanía. ${ }^{32}$

A lo anterior han contribuido los crecientes problemas prácticos asociados con la tensión que deriva de los reclamos de soberanía que hacen los Estados y otros actores institucionales - tanto domésticos como internacionales - a través del planteamiento de conflictos de competencia, así como problemas de interpretación y aplicación de leyes. En su solución, la pregunta implícita es ¿cuál es o debe ser la entidad soberana? Claramente, esta situación se vuelve cotidiana e intensifica en los sistemas de "gobernación en múltiples niveles" como el europeo. ${ }^{33}$

No obstante, un sector importante de la comunidad académica sostiene que el concepto de soberanía no debe ser abandonado bajo el argumento de que el Estado continuará siendo el eje del nuevo orden nacional e internacional. Aunque dentro de este sector muchos que reconocen que el concepto debe ser adaptado a los tiempos actuales lo que implicaría desasociarlo del Estado-nación y extenderlo al ámbito supranacional e internacional. Los menos - aunque rápidamente en aumento - piensan el concepto es ya obsoleto, por lo que se deben construir conceptos nuevos para describir realidades también nuevas.

MacCormick fue uno de los primeros en estudiar la naturaleza política y jurídica de la UE sin recurrir a la noción tradicional de soberanía. ${ }^{34}$ Su concepto de "post-soberanía" (post-sovereignty) — en boga hoy en Europa - intenta contribuir a una mejor explicación del desplazamiento de poder político de los Estados miembros a favor de la UE. Esta estrategia ha inspirado la acuñación de términos alternativos, entre los que se encuentran: "soberanía flotante",35 "soberanía tardía", 36 "soberanía mix-

32 Besson, Samantha, op. cit., nota 30, p. 2.

33 Aalberts, Tim, "The future of sovereignty in multilevel governance Europe: A constructivist reading”, Journal of Common Market Studies, vol. 42, núm.1, 2004.

34 MacCormick. Neil, op. cit., nota 7.

35 Kostakopoulou, Dora, "Floating sovereignty: A pathology or a necessary means of State evolution?", Oxford Journal of Legal Studies, vol. 22, 2002.

36 Walker, Neil, "Late sovereignty in the European Union", en Walker, Neil (ed.), op. cit., nota 25 . 
ta" ${ }^{37}$ y "soberanía domesticada". ${ }^{38} \mathrm{El}$ hecho de que todas las nociones anteriores utilicen la palabra soberanía para contrastar una realidad distinta a la pasada sugiere la urgente necesidad de un referente conceptual distinto.

Si se acepta que el concepto de soberanía estatal se ha transformado, la pregunta que sigue es: ¿Cómo afecta dicha transformación a la naturaleza del Estado-nación? Aunque ya se habla —en la lógica de la "post-soberanía- de la emergencia de un "post-Estado" (post-State), la realidad es que la pregunta está en espera de respuestas. El recurso de echar mano a los conceptos de soberanía y Estado no es más que un reconocimiento del marcado dinamismo de nuestros tiempos. Por ello, y ante la falta de evidencia y de herramientas analíticas nos quedamos, por el momento, con la noción provisional de "Estado transicional" que propone Saucedo González. ${ }^{39}$

\section{La UE: ¿Una nueva “especie institucional”?}

Otra de las grandes preguntas teóricas que plantea este artículo tiene que ver con la naturaleza política y jurídica de la UE. Como argumentamos en otro lugar, el que la UE sea un fenómeno institucional sin precedentes explica los problemas teóricos y prácticos que se han enfrentado para definirla y catalogarla. ${ }^{40}$ Uno de ellos lo constituye la tendencia, todavía muy extendida, de querer tipificarla a la luz de los marcos conceptuales que ha construido la filosofía política, el derecho, la ciencia política y las "relaciones internacionales" para explicar el orden westfaliano. Los ejemplos permean mucha de la literatura actual.

La asimilación de la UE al Estado-nación ha llevado a la acuñación de términos tales como "unión de Estados", "mega-Estado" y "supra-Estado". En este mismo orden de ideas, se discute si la UE constituye una confederación o una federación de Estados. Fisher y otros van más allá al considerar que el proceso europeo actual transita de una con-

37 Bellamy, Richard, "Sovereignty, post-sovereignty and pre-sovereignty: The three models of the State, democracy and rights within the EU", en Walker, Neil (ed.), op. cit., nota 25.

38 Besson, Samantha, "The taming of sovereignty: Review of N. Walker's Sovereignty in Transition”, International Journal of Constitutional Law, vol. 2, núm. 3, 2004.

39 Saucedo González, José Isidro, "El Estado transicional", Boletín Mexicano de Derecho Comparado, nueva serie, año XXXVIII, núm. 112, enero-abril de 2005, pp. 223-271.

40 Torres Espinosa, Eduardo, op. cit., nota 23, pp. 505-507. 
federación a una federación. ${ }^{41}$ Sin duda, detrás de esta interpretación está la imagen de las negociaciones de Pennsylvania que condujeron al nacimiento de los Estados Unidos. La crítica sería que los integrantes de la UE no son "colonias" sino Estados y que estamos en 2005 y no a finales del siglo XVIII. Sin duda, el asunto es teóricamente mucho más complejo.

Desde la perspectiva de las "relaciones internacionales" ha sucedido algo similar. Así, y tomando como modelo a la Organización de las Naciones Unidas, el considerar a la UE como una "organización internacional" más se convirtió en lugar común. En el mejor de los casos, la UE fue equiparada a una "organización intergubernamental", sin tomar en cuenta que la noción de inter-gubernamentalismo está limitada a la mera cooperación, generalmente sectorial, entre Estados sin que halla de por medio una tangible delegación transnacional de poder político. Por ello, muchos autores tratado de comprobar que la UE es mucho más que una simple organización intergubernamental. ${ }^{42}$

En aras de la precisión, se habla ahora de "organizaciones gubernamentales internacionales", las cuales se dividen en intergubernamentales, transgubernamentales y supranacionales..$^{43}$ Se indica que las primeras son organizaciones no unitarias, de corte westfaliano creadas por Estados, las cuales carecen de facultades para emitir decisiones obligatorias que afecten a uno o más de sus miembros. Por su parte, las organizaciones transgubernamentales están compuestas por actores gubernamentales de diferentes procedencias y niveles. Y su naturaleza es funcionalmente poco articulada, porosa y abierta. Finalmente, las organizaciones supranacionales han logrado "adquirir esferas de autonomía institucional que desafían la lógica territorial del Estado-nación". ${ }^{44}$

El problema con la definición del último tipo de organizaciones tiene que ver con la ambigüedad del término supranacionalismo, el cual es generalmente entendido "como una transferencia de autoridad legal y de

41 Fisher, Joschka, op. cit., nota 27.

42 Stone Sweet, Alec y Sandholtz, Wayne, European integration and supranational governance, Oxford, Oxford University Press, 1998.

43 Simmons, Beth A. y Martin, Lisa L., "International organizations and institutions", en Carlsnaes, Walter, Risse-Kappen, Thomas y Simmons, Beth A. (eds.), Handbook of International Relations, Londres, Sage, 2003.

44 Egeberg, Morten, "Organising institutional autonomy in a political context", ponencia presentada en la Conferencia Institutional Dynamics and Democracy in the EU, organizada por ARENA, Oslo, Suecia, 3 y 4 de octubre de 2003. 
poder para tomar decisiones de los Estados miembros a una institución o cuerpo internacional". ${ }^{45} \mathrm{La}$ distinción entre "soberanía compartida" (pooled sovereignty) y "soberanía delegada" (delegated sovereignty) no es suficiente para clasificar a las organizaciones supranacionales existentes. La UE es un buen ejemplo, si bien el Consejo de Ministros muestra rasgos de "soberanía compartida", la Comisión Europea, el Parlamento Europeo y la Corte Europea de justicia los muestra de "soberanía delegada".

Para avanzar, entonces, habría que identificar las posibles clases de transferencia de autoridad legal y de poder decisorio que existen o podrían existir. Pero sobre todo, se tendría que otorgar una mayor atención a las características institucionales de las entidades destinatarias de esa autoridad y poder, así como al nivel de desarrollo institucional que han alcanzado y de autonomía real de que disfrutan expresado en su poder real para establecer reglas, procedimientos e instituciones. A pesar de la gigantesca literatura que se ha escrito sobre la UE, todavía no se valora suficientemente el impacto transformativo de su novedoso arreglo institucional sobre el orden westfaliano. Ya es tiempo de que el nuevo institucionalismo incluya a las "relaciones internacionales".

Sin duda, un primer paso lo ha dado el llamado constructivismo. ${ }^{46}$ Adicionalmente, multiplican los esfuerzos por estudiar y definir a la UE a partir de la construcción de nuevos conceptos. ${ }^{47}$ No obstante, hasta en tanto no se desarrollen nuevos enfoques, la atipicidad de la UE continuará rechazando su identificación y clasificación de acuerdo con concepciones preexistentes. Por todo lo anterior, la UE no ha dejado de constituir un "OPNI", es decir, un "objeto político no identificado", en espera de ser bautizado. ${ }^{48}$

45 McLean, Iain y McMillan, Alister, op. cit., nota 3, p. 527. Las cursivas son de quién escribe estas líneas.

46 Un resumen de esta novel corriente teórica en el ámbito de las "relaciones internacionales puede encontrarse en Hay, Colin, op. cit., nota 28, pp. 19-25.

47 Véase, por ejemplo, a Schmitter, P. C., "Imagining the future of the Euro-polity with the help of new concepts", en Marks, Gary et al. (eds.), Governance in the European Union, Londres y California, Sage, 1996.

48 Huacuja Acevedo, José Antonio, "La Unión Europea y el fascismo", ponencia presentada en el Coloquio De la derrota del fascismo al sistema de control internacional contemporáneo, México, Coordinación de Posgrado en Derecho de la UNAM, FES Acatlán, 11 de mayo de 2005. 


\section{EL DERECHO CONSTITUCIONAL E INTERNACIONAL ANTE EL CASO EUROPEO}

El derecho constitucional moderno tiene su origen en la dinámica centralizadora que detonó la Paz de Westfalia y con el movimiento europeo de codificación de normas jurídicas que dio inicio en el siglo XVIII. Así, la teoría constitucional supone una relación simbiótica entre el Estado y su orden jurídico, toda vez que se considera que el segundo es constitutivo del primero. ${ }^{49}$ En este orden de ideas, la soberanía estatal emerge como "el poder jurídico más absoluto sobre la Tierra" y sobre el cual "no hay apelación". ${ }^{50}$ Ello explica que todo orden jurídico nacional se presente como un sistema piramidal altamente jerarquizado, donde la Constitución ocupa el sitio más elevado. Su carácter de "lex legum" implica que su "su validez no puede derivar de otra superior". ${ }^{1}$

En una lógica impecable, el principio de "supremacía constitucional" conduce al principio de "rigidez", por el cual una Constitución sólo puede ser reformada bajo "supuestos dificultados". ${ }^{52}$ Asimismo, justifica la introducción de mecanismos de control constitucional para proteger a esta instancia normativa suprema frente a posibles amenazas provenientes de la actuación de los órganos estatales que la propia constitución instituye. Desde un enfoque westfaliano, estos principios "auto-evidentes" serían también reconocidos en el ámbito internacional, bajo el argumento de que "el derecho internacional presupone la existencia de los órdenes jurídicos nacionales". 53

De esta manera, el desarrollo de las relaciones internacionales dio lugar "al surgimiento de un derecho internacional pero no supranacional" ${ }^{54}$ A ello contribuyó la visión positivista que consideraba que en la arena internacional no participaban más que estados soberanos, a los cua-

49 MacCormick, Neil, op. cit., nota 7.

50 Valaskakis, Kimon, op. cit., nota 8, p. 2.

51 Kelsen, Hans, Teoría general del derecho y del estado, traducción de Eduardo García Máynez, segunda edición, México, UNAM, Textos Universitarios, 1995.

52 Schmitt, Carl, Teoría de la Constitución, México, Editorial Nacional, 1970, pp. 47-50. Más recientemente, Arend Lijphart ha constatado que un número importante de las democracias actuales tienen constituciones rígidas, lo que implica que para su modificación se requieran, por lo menos, dos tercios o más de los miembros del órgano legislativo. Patterns of democracy: Government forms and performance in thirty-six countries, New Heaven y Londres, Yale University Press, 1999.

53 Kelsen, Hans, Teoría general del derecho y del estado, traducción de Eduardo García Máynez, segunda edición, México, UNAM, Textos Universitarios, 1995, p. 407.

54 Valaskakis, Kimon, op. cit., nota 8, p. 4. 
les correspondía el monopolio de la expedición de leyes, entendidas como mandatos estatales impuestos por la fuerza. La ausencia de otros actores condujo a la imagen de que el derecho internacional, al carecer de un respaldo soberano, es "necesariamente imperfecto". ${ }^{55}$ Así, se subordinaron sus alcances al derecho constitucional de los Estados-nación.

La "globalización jurídica", en general, y el derecho comunitario, en particular, se han encargado de exhibir el debilitamiento, gradual pero consistente, de la mayoría de los supuestos y principios en que descansa el derecho constitucional convencional. En primer lugar, existe una clara tendencia a que los Estados permitan, de facto o de jure, la aplicación interna del derecho internacional y de las normas de las organizaciones internacionales a las que pertenecen. Por ejemplo, las constituciones de Alemania (artículo 25) y de Italia (artículo 10) establecen que sus disposiciones jurídicas deben respetar la ley consuetudinaria internacional, so pena de ser inconstitucionales.

Uno de los campos donde se observan mayores tensiones entre el derecho nacional e internacional es el correspondiente a los tratados internacionales. La razón fundamental es que sus efectos, con mucha frecuencia, plantean serios problemas relacionados con el principio de supremacía constitucional, con el principio internacional de pacta sunt sevan$d a$ (los tratados deben ser cumplidos), y con la falta de instancias supranacionales eficaces para la resolución de conflictos. Las resistencias a la internación del derecho internacional al nacional son magnificadas por el hecho de que las interacciones entre Estados no sólo se han multiplicado, sino que se intensificarán en los tiempos por venir. ${ }^{56}$

En virtud que su existencia deriva de tratados internacionales, la UE es el caso más incómodo para el derecho constitucional y el internacional. Ciertamente, el Tratado de Roma (1957) sentó las bases para que los acuerdos alcanzados entre los Estados participantes se incorporaran a los sistemas jurídicos nacionales, así como para la creación de instituciones jurídicas propias encargadas de vigilar su observancia. En un primer momento, el derecho comunitario constituyó un sistema convencional de derecho internacional ya que sólo obligaba a los Estados miembros. Sin

55 McLean, Iain y McMillan, Alister, op. cit., nota 3, p. 269.

56 Si se desea abundar sobre esta problemática en el caso mexicano, véase a Palacios Treviño, Jorge, Tratados, legislación y práctica en México, tercera edición, México, Secretaría de Relaciones Exteriores, 2001; y a Walss Aureoles, Rodolfo, Los tratados internacionales y su regulación jurídica en el derecho internacional y el derecho mexicano, primera edición, México, Porrúa, 2001. 
embargo, cuando reconoció derechos a los individuos se transformó en algo más parecido al derecho constitucional nacional. ${ }^{57}$

Atendiendo al acelerado desarrollo del derecho comunitario, en los últimos años un creciente número de académicos han llamado la atención sobre la importancia de incluir la dimensión jurídica en el estudio del proceso de integración europea, así como de sus instituciones. En particular, se recomienda estudiar, desde esta perspectiva, el relevante papel que ha jugado el Tribunal de Justicia europeo. ${ }^{58}$ La razón es que este órgano jurisdiccional tuvo el efecto de constitucionalizar al Tratado de Roma, lo que ha implicado una transformación radical del derecho comunitario. ${ }^{59}$

A principios de 2000, la "Declaración relativa al futuro de la Unión" del Tratado de Niza reconoció la necesidad de simplificar los tratados fundacionales "con el fin de clarificarlos y facilitar su comprensión, sin cambiar su significado". Justo dos años después, el Consejo Europeo —reunido en la ciudad belga de Laekena — planteó "la cuestión de si la simplificación y la reorganización de los Tratados no deberían preparar el terreno para la adopción de un texto constitucional". ${ }^{60} \mathrm{La}$ aceptación que tuvo esta revolucionaria propuesta condujo a la elaboración de un proyecto de Tratado por el cual se Instituye una Constitución para Europa, el cual fue aprobado por los representantes de los Estados miembros a mediados de 2004.

Aunque este tratado no ha entrado en vigor por las razones que explicaremos en la siguiente sección, la constitución que propone introduce avances e innovaciones que no pueden pasar inadvertidos. Desde un punto de vista formal, dos son los principales avances. El primero de ellos es la concentración en un solo ordenamiento del antes disperso derecho comunitario con lo se busca hacerlo más accesible. ${ }^{61}$ El segundo avance lo

57 Wincott, Daniel, "The Court of Justice and the European policy process", en Richarson, Jeremy (ed.), European Union: Power and policy-making, segunda edición, Londres y Nueva York, Routledge, serie Routledge Research in European Public Policy, 2001, p. 181.

58 Véase, por ejemplo, a Weiler, John., "Community, member states and European integration: Is the law relevant", Journal of Common Market Studies, vol. 20, 1982, pp. 1-2.

59 Burley, Anthony y Mattli, Walter, "Europe before the Court: A political theory of legal integration", International Organization, vol. 47, núm. 1, 1993.

60 Declaración de Laeken sobre el futuro de la Unión Europea, Bélgica, Consejo Europeo, 15 de diciembre de 2001.

61 Cabe destacar que en la segunda parte de la constitución se incorpora, en forma integra, la Carta de los Derechos Fundamentales de la Unión Europea. Esta Carta fue aprobada en la ciudad 
constituye la clarificación que se hace de las funciones a cargo de las instituciones y órganos de la UE. Hasta aquí, la Constitución no modifica la esencia de los tratados fundacionales de esta última.

Sin embargo, el texto constitucional incorpora seis innovaciones que tienen importantes implicaciones teóricas y doctrinales para el derecho constitucional. Primera, se otorga personalidad jurídica a la UE (art. I-7). Segunda, se le reconoce una bandera y un himno propios, y se agrega al euro y al Día de Europa (9 de mayo) como sus símbolos (art. I-8). Tercera, se delimita su ámbito de competencia exclusiva (art. I-13). Cuarta, se introduce la figura del ministro de Asuntos Exteriores de la Unión para mejor instrumentar una política exterior y de seguridad común (art. III-340). Quinta, se amplían considerablemente las facultades del Tribunal de Justicia europeo (arts. III-353 y ss). Sexta, a diferencia de los sistemas federales existentes, se establece que todo Estado miembro podrá decidir retirarse de la Unión (art. I-60). ${ }^{62}$

Aunque las innovaciones anteriores están todavía por procesarse plenamente en los ámbitos académicos, algunos ven en ello un claro distanciamiento entre la Constitución europea y la teoría constitucional dominante. En contraste, están los que afirman que el derecho comunitario europeo, "si bien es autónomo, no es independiente" del derecho internacional o, dicho en otros términos, que el primero es en realidad "un subordenamiento jurídico" del primero. ${ }^{63}$ Sin embargo, el reciente rechazo a la Constitución europea expresado por los franceses y holandeses introduce una tercera variable al debate: la democracia europea.

\section{PERO, ¿TIENE FUTURO EL PROYECTO CONSTITUCIONAL EUROPEO?}

El reciente proceso constitucional europeo muestra dos etapas contradictorias. La primera se llevó a cabo sin sobresaltos y en medio de un gran optimismo. En efecto, el proyecto de tratado constitucional fue ela-

de Niza el 7 de diciembre de 2000, y tutela los siguientes derechos: dignidad, libertad, igualdad, solidaridad, ciudadanía y justicia.

62 Los artículos mencionados entre paréntesis corresponden al "Tratado por el cual se establece una Constitución para Europa", Diario Oficial la Unión Europea, núm. C 310, 16 de diciembre de 2004.

63 Acosta Estévez, José B., "La interdependencia entre el derecho internacional y el derecho comunitario europeo", Anuario Mexicano de Derecho Internacional, vol. 5, 2005, pp. 13-50. 
borado en un tiempo récord, aprobado sin voto en contra por la Convención Europea en junio de 2003, y presentado al presidente del Consejo Europeo en Roma un año después. ${ }^{64}$ Acto seguido, los representantes de los 25 Estados miembros y de los tres países candidatos (Bulgaria, Rumania y Croacia) suscribieron, unánimemente, el Tratado por el cual se Instituye una Constitución para Europa, el 29 de octubre de 2004. Poco antes, el presidente de la Comisión Europea había expresado su confianza en que la UE contaría con una Constitución, en los siguientes términos:

El 25 de marzo de 1957, en esta misma sede solemne, Europa respondió a las consecuencias de la guerra mundial y a la guerra fría con un proyecto sin precedentes de construcción de una democracia supranacional. Hoy Europa reafirma su forma de organización política original y única para responder al reto de la globalización, promover sus valores de paz y solidaridad y ejercer el papel que le corresponde en la escena internacional. ${ }^{65}$

Para entender mejor los sucesos que siguen, es necesario recordar que la entrada en vigor del tratado constitucional había quedado condicionada a su ratificación por parte de todos y cada uno de los países signatarios, "con arreglo a sus respectivos procedimientos constitucionales". De acuerdo con ellos, al 27 de mayo pasado habían cumplido esta exigencia — por vía parlamentaria o plebiscitaria - nueve de los veinticinco Estados miembros. ${ }^{66}$ Hasta aquí, las cosas iban viento en popa, pero el panorama se ensombrecería sólo dos días después.

En Francia, el referéndum obligatorio, celebrado el domingo 29 de mayo de 2005, arrojó que casi 55 por ciento de sus ciudadanos estaban en contra de una Constitución europea. De inmediato, el presidente de la Comisión Europea, José Manuel Barroso, alertó sobre un posible "riesgo

64 Proyecto de Tratado por el que se instituye una Constitución para Europa, Bruselas, Convención Europea, 18 de julio de 2003.

65 Prodi, Romano, "Firma de la Constitución Europea", discurso pronunciado en la ciudad de Roma el 29 de octubre de 2004, Unión Europea, speech/04/479. Las cursivas son de quien escribe estas líneas.

66 Estos países son: Lituania (11 de noviembre de 2004), Hungría (20 de diciembre 2004), Eslovenia (1 de febrero de 2005), España (20 de febrero de 2005), Italia (6 de abril de 2005), Grecia (19 de abril de 2005), Eslovaquia (11 de mayo de 2005), Austria (25 de mayo de 2005) y Alemania (27 de mayo). Vale la pena que en Bélgica el tratado constitucional fue aprobado por el senado el 28 de abril y por la cámara baja el 19 de mayo de mayo de 2005, y se espera que las asambleas locales lo aprueben próximamente. 
de contagio". Este escenario se materializó tres días después, cuando, el 1 de junio del mismo año, los holandeses también dijeron no a la Constitución por un abrumador 61.7 por ciento. Ante ello, los representantes de la UE expresaron su respecto por las decisiones, pero reiteraron que la Constitución europea era la mejor respuesta a una "mundialización acelerada". ${ }^{67}$

En particular, dichos representantes lamentaron el rechazo a la Constitución por parte de los ingleses, cuyo país había sido "desde hace 50 años uno de los motores esenciales de la construcción de nuestro futuro común". Ante la negativa francesa y holandesa, el primer ministro Tony Blair declaró que era muy pronto para saber si Gran Bretaña seguiría adelante con el referéndum programado para principios del 2006. Sin embargo, el 6 de junio el secretario de relaciones inglés, Jack Straw, informó a la Cámara de los Comunes que el gobierno había decidido posponer dicha consulta de manera indefinida. ${ }^{68}$ Desde su reelección en mayo, Blair se había finalmente convencido de que sería incapaz de ganar el referéndum.

Las verdaderas y últimas causas del "no" francés y holandés a la Constitución europea están por estudiarse. No obstante, en una primera lectura se ha afirmado que los electores franceses protestaron "contra la ampliación de la Unión Europea y la economía liberal", mientras que en Holanda "los electores protestaron contra la ampliación y contra la alta contribución holandesa al presupuesto europeo". ${ }^{69}$ Lo que ha llamado menos la atención es que, a diferencia del caso francés, el plebiscito holandés no era jurídicamente obligatorio, pero el gobierno decidió adoptar su resultado. Este hecho sugiere la importancia que han adquirido los ciudadanos europeos en la toma de las grandes decisiones. ${ }^{70}$

Aunque se habla de que la UE enfrenta una profunda y peligrosa crisis, se pueden hacer cuatro lecturas menos pesimistas de los eventos an-

67 Declaración conjunta del presidente del Parlamento Europeo, Josep Borrell Fontelles, del presidente del Consejo Europeo, Jean-Claude Juncker. y del presidente de la Comisión Europea José Manuel Barroso, Bruselas, Unión Europea, Informe de Prensa núm. IP/05/627, 2 de julio de 2005.

68 Cabe indicar que el tratado constitucional había sido ya aprobado por la Cámara de los Comunes, el 9 de febrero de 2005.

69 Donnelly, Brendon, "The UK debate", The Federal Trust for Education \& Research, EU Constitution Newslatter, junio de 2005, p. 6.

70 Sobre este tema, véase a Nicolaïdis, Kalypso, "The new constitution as European democracy?, Londres, The Federal Trust for Education \& Research, Ensayo núm. 38/03, diciembre de 2003. 
teriores. Primera, el proceso europeo de integración puede ser visto como una sucesión interminable de crisis importantes que han sido eventualmente resueltas. Segunda, con o sin Constitución, la UE cuenta un sólido andamiaje institucional y con un eficaz sistema jurídico que le asegura su sobrevivencia. Tercero, el "no" francés y holandés tiene más que ver con la política interna de esos países con el desempeño económico de sus gobiernos, que con el tema constitucional. Cuarta, se trata sólo de dos casos en un universo ampliado a veinticinco Estados miembros a partir de mayo de 2004, y el proceso de ratificación continua. ${ }^{71}$

Es realmente en otros círculos donde la posibilidad de reconocerle soberanía jurídico-política a la UE —a través de una Constitución- ha encontrado una mayor resistencia. Por ejemplo, un abogado del Tribunal de Justicia europeo recuerda a los "promotores de la supremacía del derecho comunitario" que los tratados fundacionales de la UE "no pueden ser considerados como una primera Constitución histórica al momento de su firma, ni tampoco dichos tratados se desarrollaron como una Constitución con el paso del tiempo". Por lo tanto, "el asunto de la kompetenz-kompetenz judicial permanece en los Estados miembros y en sus cortes". ${ }^{72}$ No cabe duda, la ideología y el discurso de los defensores del Estado-nación se resiste a perder terreno.

Pero, ¿tiene futuro la Constitución europea? Para abordar esta difícil pregunta, haremos uso de un texto clásico muy conocido, pero al mismo tiempo poco aprovechado en su riqueza teórica-práctica. En su afán por entender por qué el rey prusiano Friedrich Wilhelm III y su sucesor fueron incapaces de cumplir su promesa de dar a su país una Constitución, Lassalle llegó a una conclusión paradigmática: los "problemas constitucionales no son, primariamente, problemas de derecho, sino de poder". ${ }^{73}$ Desde esta perspectiva, toda Constitución estatal no hace más que reflejar en el papel la "suma de los factores reales de poder que rigen en ese país". 74

71 Por ejemplo, el 30 de junio pasado, el gobierno de Chipre ratificó el tratado constitucional.

72 Schilling, Theodor, "The autonomy of the community legal order: An analysis of possible foundations", en Schilling, Theodor, Weiler, J. H. H. y Haltern, Ulrich R., Who in the Law is the Ultimate Judicial Umpire of European Community Competences?: The Schilling-Weiler/Haltern debate, Harvard Jean Monnet Working Paper, núm. 10, 1996 (disponible en http://www.jeanmonnet program.org/papers/96/9610.html).

73 Lasalle, Ferdinand, ¿Qué es una constitución?, México, Colofón, 1998, p. 47. Las cursivas se encuentran en el texto original.

74 Ibidem, p. 19. 
En los tiempos de Lassalle, como él mismo lo constató, los actores más influyentes eran el monarca, el ejército, la gran burguesía y los banqueros. Si se acepta su modelo teórico, no habría más que identificar a la pluralidad de actores que actúan en el marco de la UE. En vez de un monarca, vemos hoy a los jefes de Estado de los países miembros negociar con los ejecutivos de la UE, y con los de otros Estados. La gran burguesía y los banqueros han sido reemplazados por las grandes corporaciones transnacionales. Sin embargo, algunas de ellas trabajan para no perder su nacionalidad europea ni las ventajas que ofrece ese mercado.

Sólo restaría hablar de un actor clave: los ejércitos. La respuesta no la proporciona el que escribe sino Schuman y Monnet, quienes siempre creyeron que la integración económica, política y social era el mejor inhibidor de las amenazas bélicas. Por ello, resulta más provechoso hablar de la democracia europea. Es cierto, se exige a la UE - como sucede en todo sistema político - mayor "efectividad y legitimidad" y se cuestiona severamente el nivel democrático alcanzado. ${ }^{75}$ Ciertamente, hay problemas. Sin embargo, lo que hoy parece claro es que, con o sin Constitución, la UE llegó para quedarse.

\section{REFLEXIONES FINALES}

El título de esta última sección reconoce que en un trabajo con los objetivos de éste no es posible hacer afirmaciones conclusivas, sino sólo el planteamiento de ideas encaminadas a estimular la reflexión sobre la temática abordada. En primer lugar, la UE nos recuerda que Estado-nación no siempre ha estado presente en las sociedades humanas, sino que es un fenómeno moderno. ${ }^{76} \mathrm{Si}$ el Estado fue precedido por otras formas menos complejas de organización política, no hay razón para creer que no pueda ser reemplazado por estructuras más complejas y cualitativamente diferentes a las que lo precedieron.

Por otro lado, nuestro argumento parece confirmar la hipótesis de que lo que ocurre en el medio ambiente es el motor principal de "todo cambio institucional" y el factor que determina el desarrollo gradual de

75 Eberlein, Burkard y Kerwer, Dieter, op. cit., nota 24.

76 Para confirmar lo anterior basta sólo con releer a Coulanges, Fustel, La ciudad antigua: Estudio sobre el culto, el derecho y las instituciones de Grecia y Roma, décima edición, México, Porrúa, colección Sepan cuantos..., núm. 181, 1996. 
"las características particulares" de las instituciones políticas, que plantea el nuevo institucionalismo. ${ }^{77}$ En este trabajo hemos sostenido que Estado-nación es producto del transito del feudalismo al capitalismo, así como que la integración europea puede ser vista como una reacción a los grandes eventos económicos y políticos que han ocurrido a partir de la posguerra. En estos tiempos, la globalización de la economía conduce, necesariamente, a la internacionalización de las instituciones.

El rasgo distintivo de la UE es su naturaleza institucional supra-estatal. Como toda institución política ha logrado construir sus propias rutinas, reglas, normas, convenciones, roles, prácticas, procedimientos, tradiciones, rituales y valores. Este marco institucional influye, de una manera cada vez más evidente, la conducta y las decisiones de los actores políticos que se encuentran bajo su esfera de acción, incluidos los Estados miembros. Una parte importante de este arreglo normativo lo constituye el derecho comunitario, el cual pareciera que agrega, desde arriba, un nuevo nivel de gobierno a los sistemas jurídicos nacionales.

Parece claro que la atipicidad de UE ha puesto en aprietos a la mayoría de los enfoques teóricos dominantes en las ciencias sociales. La razón es que la existencia de esa institución pone en tela de juicio los supuestos fundamentales del orden westfaliano, entre los que se encuentra la noción de soberanía estatal. Tal como sucede en el campo de la biología, el descubrimiento de una "especie institucional" puede provocar una clasificación equivocada o el reconocimiento de su novedad. Una gran resistencia a este reconocimiento ha provenido del derecho convencional, tanto constitucional como internacional.

Finalmente, insistimos en que la UE existe y se transforma día a día. Si se acepta lo anterior, el debate constitucional europeo pasaría a un segundo plano. Desde hace ya mucho tiempo, la UE cuenta con una Constitución real que ha reflejado, fielmente, la correlación de los factores reales de poder que operan en la región europea, a través de los tratados fundacionales y el derecho comunitario. Como bien apuntó Lassalle en 1862 , es necesario distinguir entre una "Constitución real y efectiva" y "la hoja de papel". ${ }^{78}$ Sí, la noción de lo estatal debe ser reformulada.

77 Vergara, Rodolfo, "Estudio introductorio", en March, James G. y Olsen, Johan P., El redescubrimiento de las instituciones: La base organizativa de la política, México, FCE-Colegio Nacional de Ciencias Políticas y Administración Pública, colección Nuevas Lecturas de Política y Gobierno, 1997, pp. 17 y 20.

78 Lasalle, Ferdinand, op. cit., nota 73, p. 25. Las cursivas están en el texto original. 